\title{
FORMULA FOR SPECIFIC VOLUMES OF SATURATED VAPORS
}

\author{
By Cyril H. Meyers
}

\section{ABSTRACT}

A formula for calculating the specific volume of saturated vapors is given. This formula expresses the specific volume of the vapor in terms of the vapor pressure, the specific volume of the liquid, and two empirical constants, one of which was the same for all the substances tried. The liquid volume need be known only approximately. For pressures up to one fourth the critical pressure, the formula represents the data on 23 substances within the experimental error. Graphs are given showing the application of the formula to 15 substances.

An equation of state applicable over a limited range, to superheated vapors, is developed from an approximation to this formula and an assumption in regard to the form of the isotherms.

In previous work on $\mathrm{CO}_{2}{ }^{1}$ it was desired to obtain from the available data the best possible value for the specific volume of carbon dioxide vapor at the triple point. With the aim of finding some relation which would make possible a reliable extrapolation to the triple point of the volumetric data at other temperatures, various functions of the vapor pressure, the orthobaric volumes, and the absolute temperature were examined. One formula was found to be particularly useful on account of its simplicity and close representation of the observed data at lower

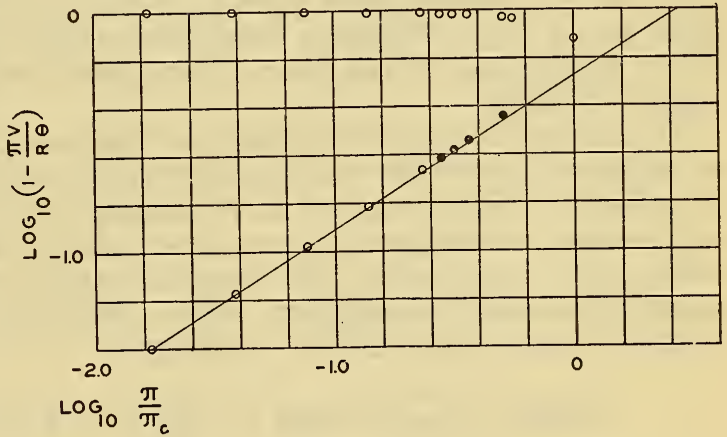

FIGURE 1.-The deviation from an ideal gas for ammonia in the vapor and the liquid phases.

Pressures for all points were taken from B.S.Sci. Papers, vol. 16, p. 1

(SP369), 1920.
O Liquid volumes from B.S.Sci. Papers, vol. 17, p. 287 (SP420), 1921; vapor volumes from B.S.Sci. Papers, vol. 18, p. 707 (SP467), 1922.

- Volumes from Beattie and Lawrence, J.Am.Chem.Soc., vol. 52, p. $1264,1929$. pressures. This formula employs a function of the deviation of the saturated fluid from the behavior of an ideal gas. An ideal gas is defined by the relation $\pi V / R \theta=1$, where $\pi$ is the pressure, $V$ the specific volume, and $\theta$ is the temperature on thermodynamic scale, and $R$ is the universal gas content divided by the molecular weight. The deviation in behavior of an actual fluid at the saturation limit from that of an ideal gas is therefore $\left(1-\frac{\pi V}{R \theta}\right)$.

The logarithm of this expression bears a simple relation to the logarithm of the vapor pressure. The application of this relation to ammonia is illustrated in figure 1. The ordinate is the logarithm of 
the deviation from an ideal gas or $\log _{10}\left(1-\frac{\pi V}{R \theta}\right)$ and the abscissa is $\log _{10} \frac{\pi}{\pi_{c}}$ where $\pi_{c}$ is the critical pressure. The points shown represent experimental data for ammonia from $-20^{\circ}$ C. up to the critical temperature. They lie along a smooth curve with the abscissa of the critical point equal to zero and with the liquid line approaching the axis $\log _{10}\left(1-\frac{\pi V}{R \theta}\right)=0$ at low pressures. Although very similar to a hyperbola the curve approaches its asymptotes more rapidly. In fact at one tenth the critical pressure the approach has been so close that the lower asymptote represents the observed value for the volume of the vapor within about 1 part in 1,000.

Similar curves were obtained for all substances tried and for most of them the abscissa of the intersection of the asymptotes is between 0.4 and 0.5. For ammonia and water on which accurate data are available the abscissa is between 0.43 and 0.44 . This numerical value depends upon the number used for the base of the logarithms which has been chosen arbitarily for convenient use with our decimal system of numbers. If the Naperian system of logarithms is used the value of the abscissa for ammonia or water is between 0.99 and 1.01 and the assumption that it is unity agrees with the observed data on all the substances examined within the experimental error. When logarithms to the base 10 are used the corresponding value is $\log _{10} e$ or 0.4343 .

The curve is of such form that for the most part is may be assumed to satisfy either of two conditions, (1) the sum of corresponding pairs of ordinates from the curve form a linear function of $\log \pi$, or $(2)$ the curve may be considered symmetrical about its axis. Either of these assumptions represents the experimental data equally well, consequently the first assumption which leads to a more simple mathematical treatment will be considered. The resulting equation is

$$
\begin{aligned}
\log _{10}\left(1-\frac{\pi u}{R \theta}\right)+\log _{10}\left(1-\frac{\pi u^{\prime \prime}}{R \theta}\right) & =A\left(\log _{10} \frac{\pi}{\pi_{c}}\right)-0.4343 \\
& =A\left(\log _{10} \frac{\pi}{2.718 \pi_{c}}\right)
\end{aligned}
$$

where $u$ is the specific volume of the liquid $u^{\prime}$ is the specific volume of the vapor, and $A$ is a characteristic empirical constant.

The number 2.718 appearing in the right-hand term was obtained empirically. Although it was used in all calculations and the method of attacking the problem led to the Naperian number $e$, a number could have been used with equally good results which was 1 percent greater for ammonia or 1 percent less for water while the tolerance permitted by the data on most of the substances was several percent. If $u$ and $\pi$ are known functions of the temperature then only the constant $A$ need be determined for the calculation of $u^{\prime}$ in the region where the equation is applicable. The linear relation fails to represent the experimental data as the critical pressure is approached, a fact which will be considered later and discussed more in detail. The relation expressed in equation (1) is illustrated by plotting $\log _{10}$ $\left(1-\frac{\pi u}{R \theta}\right)\left(1-\frac{\pi u^{\prime}}{R \theta}\right)$ as ordinate, and $\log _{10} \frac{\pi}{2.718 \pi_{c}}$ as abscissa. Such 
a diagram is shown for normal pentane in figure 2, where Young's data are represented by circles.

A considerable magnification of the scale used in figure 2 may be obtained by plotting as ordinate the differences between

and

$$
\log _{10}\left(1-\frac{\pi u}{R \theta}\right)\left(1-\frac{\pi u^{\prime}}{R \theta}\right)
$$

$$
A \log _{10} \frac{\pi}{2.718 \pi_{c}}
$$

instead of the actual values of

$$
\log _{10}\left(1-\frac{\pi u}{R \theta}\right)\left(1-\frac{\pi u^{\prime}}{R \theta}\right)
$$

This has been done in figure 3 for ammonia, carbon dioxide, and water, the abscissa remaining unchanged. Supplementary abscissas in

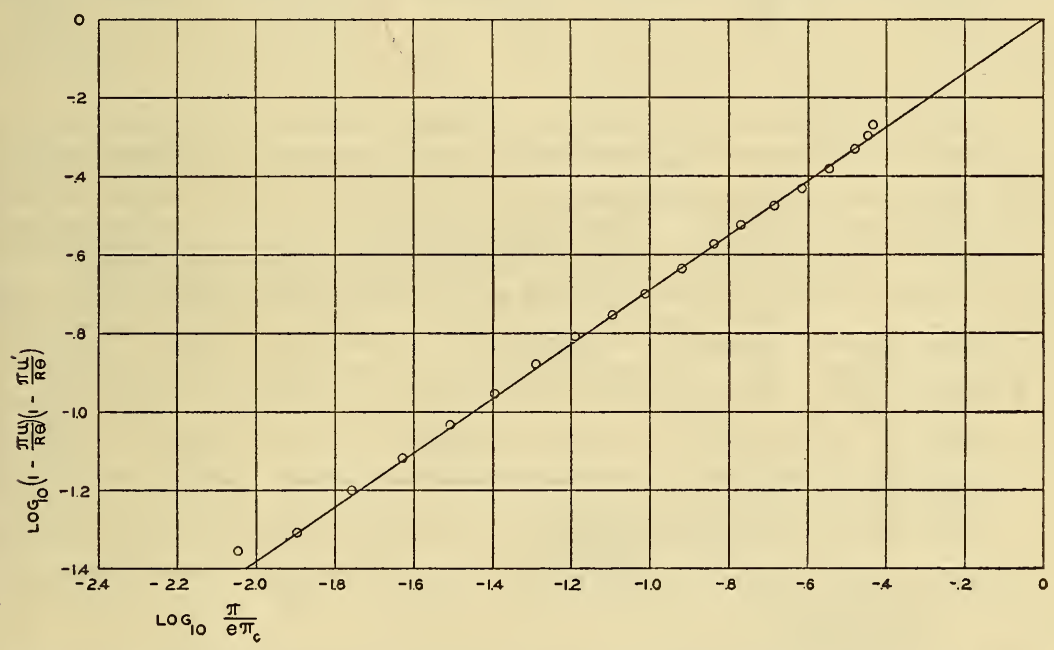

FIGURE 2.-Logarithmic sum of the terms for the liquid and the vapor of n-pentane.

degrees centigrade have been marked along the top of each part of figure 3. The dotted curves in the figures have been drawn to make possible a visual estimate of the differences between observed specific volumes of the vapor and those calculated from equation (1). The curves marked " $C C^{\prime}$ " are the loci of points for which these differences are 1 percent, those marked " $M M^{\prime}$ " are the loci for which the differences are 1 part in 1,000 .

The critical pressure of ammonia, 111.5 atmospheres, corresponding to the temperature $132.4^{\circ} \mathrm{C}$. was taken from International Critical Tables. Beattie and Lawrence ${ }^{2}$ have observed vapor pressures which are 1 percent higher in the critical region than the values previously accepted. The use of the higher critical temperature $132.9^{\circ} \mathrm{C}$. which was observed by Cardoso and Giltay ${ }^{3}$ together with the vapor pressures observed by Beattie and Lawrence would lead to a critical

2 J.Am.Chem.Soc., vol. 52, p. 1264, 1929.

3 Arch. sci. phys. nat. Geneve, vol. 34, p. 20, 1912.

13317-33-9 

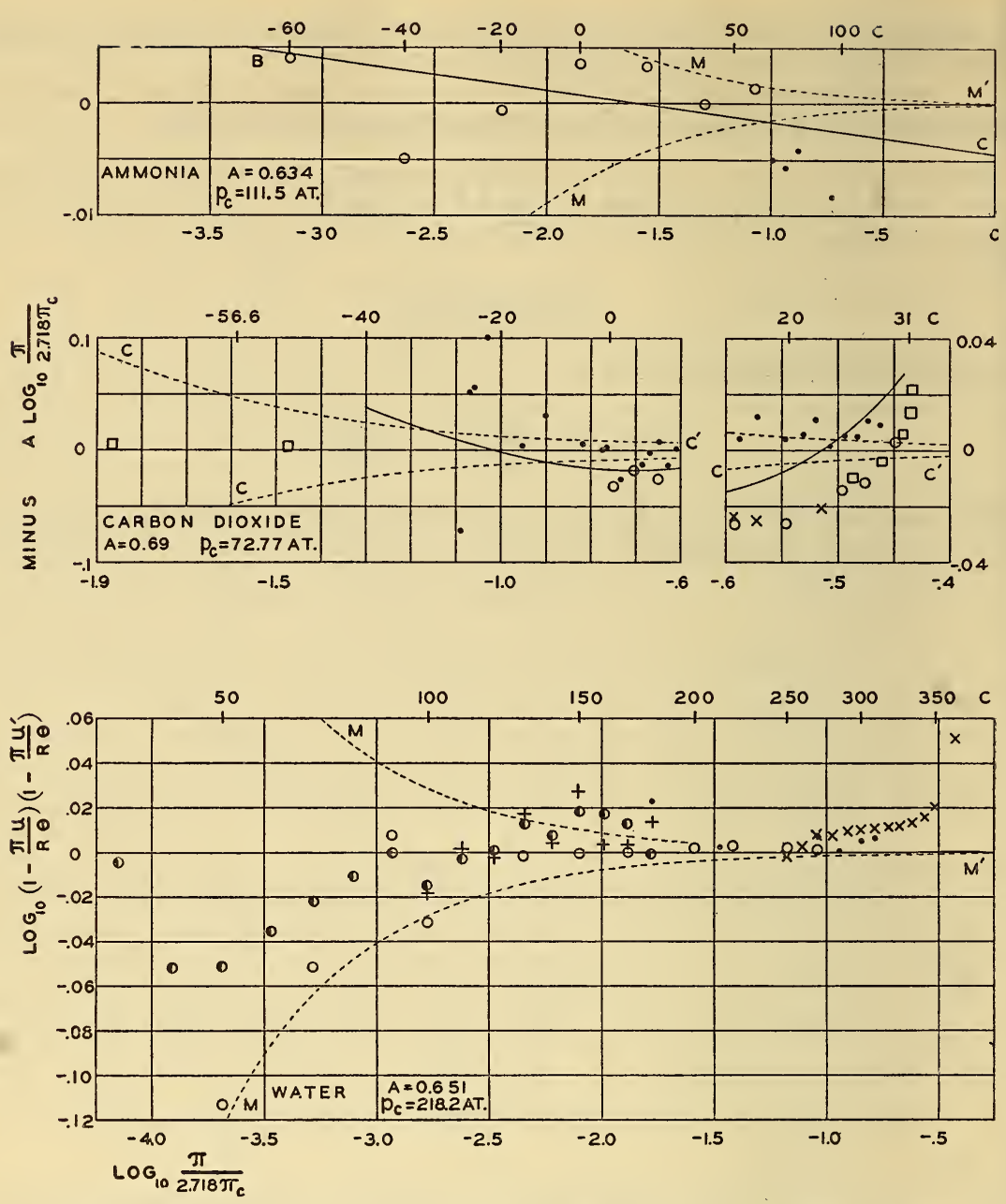

Figure 3.-Deviation charts for ammonia, carbon dioxide, and water.

The sources of the data are:

Ammonia:

Vapor pressures from B.S.Sci. Papers, vol. 16, p. 1 (SP369), 1920.

Liquid volumes from B.S.Sci. Papers, vol. 17, p. 287 (SP420), 1921.

Vapor volumes from unpublished metric tables which were used in preparing metric chart, B.S.Mis.Pub., no. 76 .

Beattie and Lawrence, J.Am.Chem.Soc., vol. 52, p. 1264, 1929.

Carbon dioxide:

Vapor pressures from B.S.Jour. Research (RP538), vol. 10, p. 381, 1933.

Liquid volumes from International Critical Tables, vol. 3, p. 236.

$\times$ Lowry and Erickson, J.Am.Chem.Soc., vol. 41, p. 2729, 1927.

Amagat Ann. chim. phys., vol. 29, p. 136, 1893. (Only a few of the published points are shown.)

Cailletet and Mathias, J.de Phys. (Ser. 2), vol. 5, p. 549, 1886.

(Left-hand figure.) Maass and Mennie, Proc. Roy. Soc. London (Ser. A.), vol. 110, p. 198, 1926. (Extrapolated from superheat.)

$\square$ (Right-hand figure.) Keesom. Comm. Phys. Lab. Leiden, no. 88, 1903.

- The continuous curve for carbon dioxide was calculated with the Clapeyron equation from Water: data on latent heat as correlated by Bridgeman in International Critical Tables, vol. 5, p. 138.

Vapor pressures and $\mathrm{d} \pi / \mathrm{d} \theta$ at $100^{\circ} \mathrm{C}$. and higher temperatures from Osborne, Stimson, Fiock, and Ginnings, B.S.Jour. Research (RP523) vol. 10, p. 155, 1933.

Vapor pressures and $\mathrm{d} \pi / \mathrm{d} \theta$ below $100^{\circ} \mathrm{C}$. and liquid volumes from Keyes and Smith, Mech. Eng. vol. 53, p. 132, 1931.

$u^{\prime}=\frac{\gamma}{\theta} \mathrm{d} \pi / \mathrm{d} \theta . \gamma$ from B.S.Jour. Research (RP209) vol. 6, p. 881, 1931; and B.S.Jour. Research (RP416), vol. 8, p. 321, 1932.

(Legend continued at bottom of page 695.) 
pressure of about 113.4, and would necessitate the use of an origin in figure 3 for ammonia about 0.0045 lower, with a value of $A$ about 0.004 smaller. The resulting equation would be represented by the straight line $B C$. Although this would improve the agreement with observed values somewhat, there would still be about 0.8 percent deviation from the specific volume at the highest pressure observed by Beattie and Lawrence. This illustrates how such a graph may be used to exhibit intercomparisons of various groups of experimental data and to adjust the value of $A$ for the best representation of the data.

The observations on carbon dioxide by Cailletet and Mathias and by Amagat appear to be equally accurate, but there are differences in the observed vapor volumes of several percent. Although the more recent observations made by Keesom and by Lowry and Erickson are in agreement with those made by Amagat, the observations of Cailletet and Mathias follow better the trend of the formula. The volumes calculated with the Capeyron equation from the latent heats as correlated by Bridgeman ${ }^{4}$ are intermediate between Amagat's and Cailletet and Mathias' data. These volumes which are represented by the continuous curve in figure 3 differ from those calculated from: equation (1) by not more than 2 percent except near the critical. At lower pressures two values for the specific volume of the saturated vapor have been calculated by extrapolating observations on the superheated vapor by Maass and Mennie. If the isotherms on the $P V, 1 / V$ chart are assumed to be linear, extrapolation of their data at $-50.3^{\circ} \mathrm{C}$. gives $56.0 \mathrm{~cm}^{3}$ per gram for the specific volume of the saturated vapor. Amagat's observations at higher temperatures indicate that the isotherms are slightly curved, the curvature in this region being almost independent of temperature. The specific volume corrected for this curvature is $56.2 \mathrm{~cm}^{3}$ per gram. By extrapolation to $-70.2^{\circ} \mathrm{C}$. of the vapor pressure equation for liquid carbon dioxide given by Meyers and Van Dusen, ${ }^{5}$ and by extrapolation of Maass and Mennie's data at this temperature, the value $189.2 \mathrm{~cm}^{3}$ per gram was obtained for the saturated vapor. The curvature of the isotherm at this temperature made no appreciable difference. The two points which represent Maass and Mennie's data in figure 3 correspond to the values 56.2 and $189.2 \mathrm{~cm}^{3}$, respectively.

The measurements on water, because of their accuracy and range, present a more exacting test for an equation than do the measurements on any other substance. Although there are consistent differences between the experimental data and values calculated from equation (1) as shown in figure 3 for water at $100^{\circ} \mathrm{C}$. and at lower temperatures, these differences are probably no greater than the experimental error.

For part of the upper range of pressures the deviations in figure 3 become negative for carbon dioxide and ammonia, which corresponds to calculated values of $u^{\prime}$ smaller than those observed. For steam

4 International Critical Tables, vol. 5, p. 138.

$\checkmark$ See footnote no. 1 .

$u^{\prime}=u+\frac{L}{\theta} \mathrm{d} \pi / d \theta$. $L$ observed by Jakob, Forsch. geb. Ingenieurw., no. 310, 1928.

+ Values of $u^{\prime}$ observed by Knoblauch, Linde, and Klebe, corrected by Jakob, same reference as preceding.

$\times$ Values of $u^{\prime}$ observed by Keyes and Smith, Mech. Eng., vol. 53, p. 132, 1931.

$u^{\prime}=u+\frac{L}{\theta} \mathrm{d} \pi / \mathrm{d} \theta$. $L$ from Jakob's formulation of Henning's data, Forsch. geb. Ingenieurw. no. $310,1928$. 
and several of the other substances to be considered later, however, there are no consistent deviations of this nature. Since these negative deviations in most cases are no greater than the experimental error, and since for carbon dioxide there are conflicting data, it is not certain whether these deviations are an indication of experimental error or of a defect of equation (1). There is no doubt, however, that the linear relation expressed in that equation fails in the critical region and gives values of $u^{\prime}$ which are too large. For steam and at least some other substances the range of the equation could be extended up to the critical point by making the quantity $A$ a function of pressure or temperature increasing rapidly from an initial value at the critical and approaching asymptotically toward a constant limiting value at lower pressures, but the data available at present are not sufficient to determine a form of this function.

The values of $A$ for 23 substances are given in table 1 . Where the value of $A$ is considered uncertain by more than 0.01 the mean value

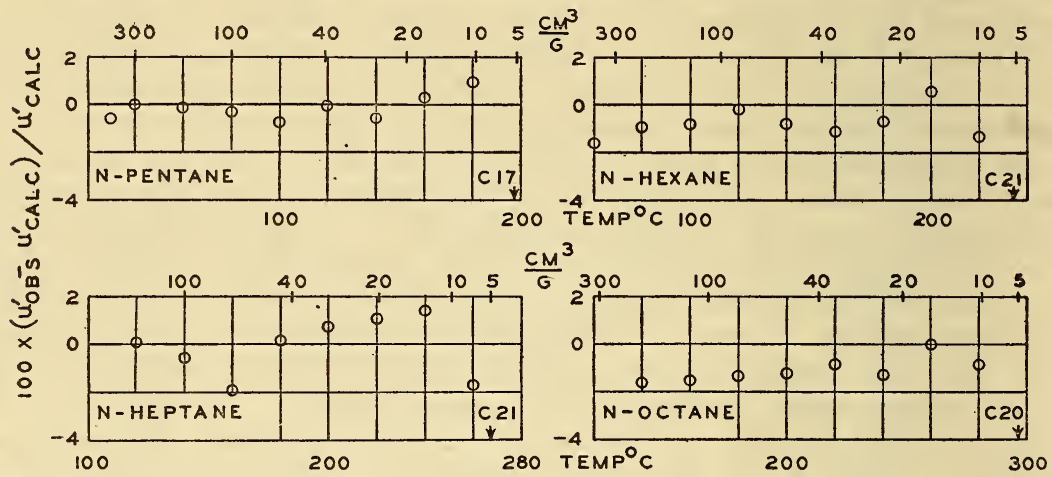

FIgURe 4.-Difference between observed specific volumes and those calculated from equation (1) with $A=0.69$.

is given together with the amount by which the value may be in error. Ammonia, water, and the alcohols which are not classed as normal substances have low values of $A$. The value 0.69 for methane is based on volumes calculated with the Clapeyron equation from unpublished data observed at the Bureau of Standards. The value of $A$ for ethane was derived from data by Porter, ${ }^{6}$ those for propane, normal and iso-butane from data by Dana, Jenkins, Burdick, and Timm, ${ }^{7}$ and those for the remainder of the series from the data by Young. ${ }^{8}$ The single value 0.69 appears to be applicable to the whole paraffin series within the experimental error of the data available. The deviations of Young's observed values for four substances of this series from those calculated with $A=0.69$ are represented in figure 4. The position of the critical point is marked by an arrow together with the letter $C$ followed by a number which indicates the percent deviation.

6 J.Am.Chem.Soc., vol. 48, p. 2051, 1926.

7 Ref. Eng., vol. 12, p. 387, 1926.

8 Proc. Roy. Dub. Soc., vol. 12, p. 374, 1909-10. 
TABLE 1.-Values of $A$ for various liquids

\begin{tabular}{|c|c|c|c|}
\hline Substance & $A$ & Substance & $A$ \\
\hline $\begin{array}{l}\text { Ammonia } \\
\text { Water } \\
\text { Carbon dioxide } \\
\text { Carbon tetrachloride } \\
\text { Benzene } \\
\text { Methanol } \\
\text { Ethanol } \\
\text { Propyl alcohol } \\
\text { Helium } \\
\text { Neon. } \\
\text { Argon } \\
\text { Xenon }\end{array}$ & $\begin{array}{l}0.634 \\
.651 \\
.69 \\
.69 \\
.70 \pm .02 \\
.61 \pm .02 \\
.67 \pm .03 \\
.64 \\
\\
\\
.72 \\
.72 \\
.72 \\
.72\end{array}$ & $\begin{array}{l}\text { PARAFFIN SERIES } \\
\text { Methane } \\
\text { Ethane } \\
\text { Propane } \\
\text { iso-butane } \\
n \text {-pentane } \\
\text { iso-pentane } \\
n \text {-hexane } \\
n \text {-octane } \\
\text { di-iso-butyl }\end{array}$ & $\begin{array}{l}.69 \\
.69 \pm .03 \\
.70 \pm .05 \\
.70 \pm .05 \\
.70 \pm .05 \\
.69 \\
.69 \\
.69 \\
.69 \\
.67 \pm .02\end{array}$ \\
\hline
\end{tabular}

A relatively large value of $A(0.72)$ was obtained for the rare gases. Determinations of the orthobaric volumes of helium by Mathias, Crommelin, Onnes, and Swallow ${ }^{9}$ and of the vapor pressure by Onnes, Weber, Keesom, Norgaard, and Schmidt ${ }^{10}$ were used to determine $A$ for helium. Since volumes and pressures were not in general measured at the same temperatures, the observed pressures were interpolated graphically.

Determinations of the orthobaric volumes of neon by Mathias, Crommelin, and Onnes ${ }^{11}$ and of the vapor pressure by Crommelin and Gibson ${ }^{12}$ were used. For interpolation between values of the vapor pressure, an equation of the form previously used for carbon dioxide ${ }^{13}$ was found convenient. The equation is

$$
\log _{10} \pi_{\text {atmos. }}=3.5740-\frac{1}{\theta}\left\{97.04-1.14(10)^{-9}\left(\theta^{2}-950\right)^{3}\right\}
$$

The average deviation from the observations is about 6 parts in 1,000 which corresponds to $0.02^{\circ} \mathrm{C}$.

For interpolation of the values of the vapor pressure of argon the equation

$$
\log _{10} \pi_{\text {atmos }}=3.9302-\frac{1}{\theta}\left\{342.20-4.0(10)^{-12}\left(\theta^{2}-13200\right)^{3}\right\}
$$

was used. The average deviation from the data by Crommelin ${ }^{14}$ and by Holst and Hamburger ${ }^{15}$ is 1.7 parts in 1,000 . The specfic volumes of argon were obtained from observations made by Mathias, Onnes, and Crommelin. ${ }^{16}$

For interpolation of the values of the vapor pressure of xenon the equation

$$
\log _{10} \pi_{\text {atmos }}=3.9992-\frac{1}{\theta}\left\{652.5-2.52(10)^{-13}\left(\theta^{2}-56000\right)^{3}\right\}
$$

was used. If it is assumed that an error of 1 meter of mercury was made in reporting the observation at $-20^{\circ} \mathrm{C}$ by Patterson, Cripps,

\footnotetext{
$?$ Leiden Comm., no. $172 \mathrm{~b}$.

${ }_{10}$ Leiden Comm., nos. $147 \mathrm{~b}, 202 \mathrm{~b}$, and $202 \mathrm{c}$.

11 Leiden Comm., no. 162b.

12 Leiden Comm., no. 185b.

13 See footnote 1 .

14 Leiden Comm., no. 138c.

16 Versl. Amst. vol. 24, p. 798, 1915; Zs. ph. Chem., vol. 91, p. 532, 1916.

${ }^{16}$ Leiden Comm., no. 131a.
} 
and Gray, ${ }^{17}$ the equation represents their data with an average deviation of 6 parts in 10,000. It represents the data at lower temperatures by Ramsay and Travers ${ }^{18}$ and by Peters and Weil ${ }^{19}$ within the precision of their data. The specific volumes of xenon were obtained from observations by Patterson, Cripps, and Gray.

The deviations of equation (1) from the observations on these rare gases are illustrated in figure 5 . When the critical point is on the scale, it is labelled $C$, otherwise it is located in the same manner as in
figure 4 .

Methyl, ethyl, and propyl alcohol, and benzene are among the numerous substances observed by Young. ${ }^{20}$ The latent heat of evaporation for methyl and ethyl alcohol, and benzene have been measured by Fiock, Ginnings, and Holton. ${ }^{21}$ This gives two sets of values for these three substances, one entirely from Young's data, and the other from the latent heat data and Young's values of $\mathrm{d} \pi / \mathrm{d} \theta$. The first set is represented in figure 6 by circles and the second set

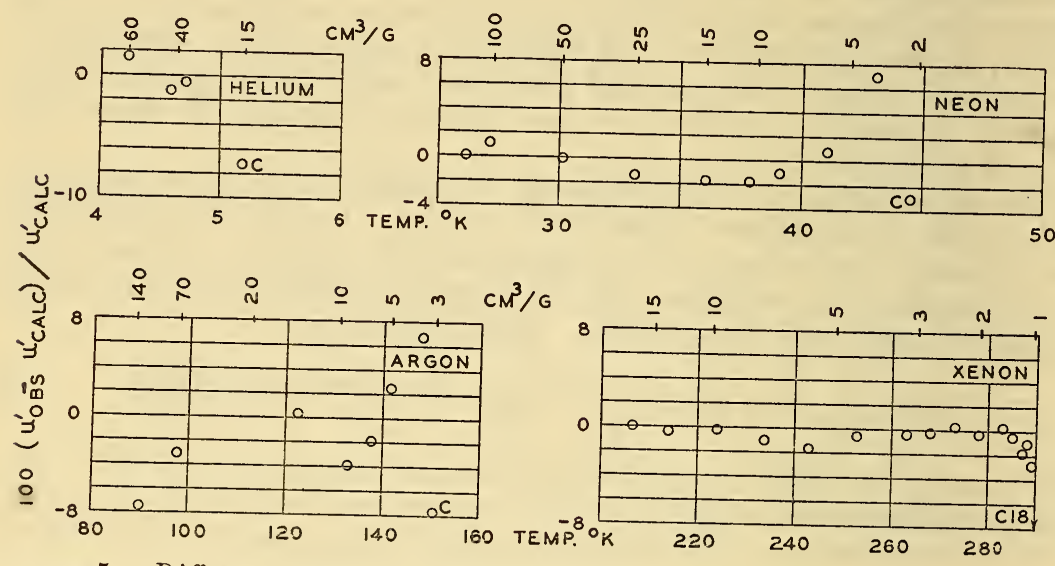
FIGURE 5.-Difference between observed specific volumes and those calculated from
equation (1) with $A=0.72$.

by black dots. The zero line and the continuous curve for each substance represent volumes calculated from the values of $A$ indicated.

Young's value for the density of methyl alcohol is higher by 0.00054 than that derived from the equation given on page 27 volume 3 of the International Critical Tables. This corresponds to a water content of about 0.3 percent. Young did not measure the density of the original sample of ethyl alcohol. It is probable that his samples of both of these alcohols contained water in sufficient quantities to render his values of both $\pi$ and $d \pi / d \theta$ uncertain. The best average value of $A$ for methanol and ethanol appears from figure 6 to be about 0.63 while the value for propyl alcohol is about 0.64 . In view of the conclusions drawn for the paraffin series and the rare gases it is reasonable to assume that a single value of $A$ applies to all the alcohols and that the best value obtainable from the data is 0.64 .

17 Proc. Roy. Soc. London, vol. 86, p. 579, 1912.

19 Phil. Trans. Roy. Soc., vol. 197, p. 47, 1901.

${ }_{20}$ Zs. phys. Chemie, vol. A148, p. 27, 1930.

no. 8 .

21 B. S. Jour. Research (R P312), vol. 6, p. 881, 1931. 
Zmaczynski's ${ }^{22}$ vapor pressure data for benzene differ consistently from Young's although the values of $d \pi / d \theta$ for the two are in good agreement up to $130^{\circ} \mathrm{C}$.

In table 2 the values of specific volume of the vapor for ammonia, carbon dioxide, and water calculated from equation (1) using the values of $A$ indicated in table 1 , are presented and compared with the best available data.

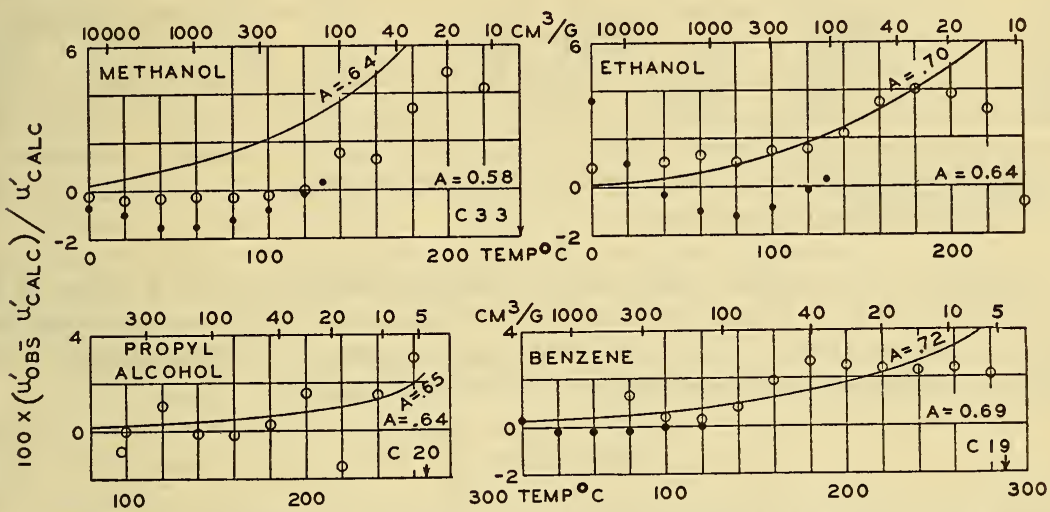

FIGURE 6.-Difference between observed and calculated specific volumes.

Pressures and volumes from Young. (See footnote 8.)

Pressures and $\mathrm{d} \pi / \mathrm{d} \theta$ from Young.

$\gamma$ from Fiock, Ginnings, and Holton. (See footnote 21.)

TABLE 2.-Comparison of calculated specific volumes with observed values for the saturated vapors of ammonia, carbon dioxide, and water

AMMONIA

\begin{tabular}{|c|c|c|c|c|c|c|c|}
\hline Temperature, ${ }^{\circ} \mathrm{C}$. & $\begin{array}{l}\text { Bureau }{ }^{1} \\
\text { of Stand- } \\
\text { ards }\end{array}$ & $\begin{array}{c}\text { Beattie }{ }^{1} \\
\text { and Law- } \\
\text { rence }\end{array}$ & $\underset{(1)}{\text { Equation }}$ & Temperature, ${ }^{\circ} \mathrm{C}$. & $\begin{array}{l}\text { Bureau 1 } \\
\text { of Stand- } \\
\text { ards }\end{array}$ & $\begin{array}{l}\text { Beattie }{ }^{1} \\
\text { and Law- } \\
\text { rence }\end{array}$ & $\begin{array}{c}\text { Equation } \\
\text { (1) }\end{array}$ \\
\hline $\begin{array}{l}-77.7^{5}-1 \\
-60 \\
-40 \\
-20 \\
0 \\
0\end{array}$ & $\begin{array}{r}\mathrm{cm}^{3} / \mathrm{g} \\
15,685 \\
4,703 \\
1,552.1 \\
623.7 \\
289.5 \\
149.4\end{array}$ & \begin{tabular}{|c|}
$\mathrm{cm} / \mathrm{g}$ \\
-1 \\
\\
\end{tabular} & $\begin{array}{c}\mathrm{cm} / \mathrm{g} \\
15,688 \\
4,703 \\
1,551.6 \\
623.6 \\
289.7 \\
149.5\end{array}$ & $\begin{array}{l}40 \\
60 \\
73.21 \\
79.37 \\
95.60\end{array}$ & \begin{tabular}{l}
$\mathrm{cm}^{3} / \mathrm{g}$ \\
43.26 \\
49.73 \\
\hdashline \\
\hdashline
\end{tabular} & $\begin{array}{r}\mathrm{cm}^{3} / \mathrm{g} \\
40 \\
35 \\
30 \\
20\end{array}$ & $\begin{array}{l}c m^{3 / g} \\
83.25 \\
48.77 \\
39.85 \\
34.83 \\
29.84 \\
19.78\end{array}$ \\
\hline
\end{tabular}

CARBON DIOXIDE

\begin{tabular}{|c|c|c|c|c|c|c|c|}
\hline Temperature, ${ }^{\circ} \mathrm{C}$. & I.C.T. ${ }^{2}$ & $\begin{array}{l}\text { Plank }{ }^{3} \\
\text { and Ku- } \\
\text { prianoff }\end{array}$ & $\underset{\text { (1) }}{\text { Equation }}$ & Temperature, ${ }^{\circ} \mathrm{C}$. & I.C.T. ${ }^{2}$ & $\begin{array}{l}\text { Plank }^{3} \\
\text { and Ku- } \\
\text { prianoff }\end{array}$ & $\begin{array}{c}\text { Equation } \\
\text { (1) }\end{array}$ \\
\hline $\begin{array}{l}-56.6{ }^{5}-\ldots \\
-50 \\
-40 \\
-30 \\
-20 \\
-10\end{array}$ & 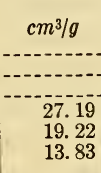 & $\begin{array}{l}\mathrm{cm}^{3} / g \\
72.22 \\
55.41 \\
38.16 \\
27.00 \\
19.47 \\
14.19\end{array}$ & $\begin{array}{l}c m^{3} / g \\
72.58 \\
55.59 \\
38.12 \\
26.80 \\
19.17 \\
13.86\end{array}$ & $\begin{array}{l}0 \\
10 \\
30 \\
311^{6}\end{array}$ & $\begin{array}{c}\mathrm{cm}^{3} / g \\
10.26 \\
7.57 \\
5.26 \\
3.00 \\
2.155\end{array}$ & $\begin{array}{c}\mathrm{cm}^{3} / \mathrm{g} \\
10.38 \\
7.52 \\
5.26 \\
2.99 \\
2.156\end{array}$ & $\begin{array}{r}c m^{3} / g \\
10.03 \\
7.19 \\
4.97 \\
2.97 \\
2.37\end{array}$ \\
\hline
\end{tabular}

1 See fig. 3 for references to data on ammonia.

2 International Critical Tables, vol. 3, p. 236.

3 Beiheft Zts. ges. Kalte-Ind., vol. 1, p. 9, 1929.

8 Triple point temperature.

22 J. chim. phys., vol. 27, p. 503, 1930. 
TABLE 2.-Comparison of calculated specific volumes with observed values for the saturated vapors of ammonia, carbon dioxide, and water-Continued

WATER

\begin{tabular}{|c|c|c|c|c|c|c|c|}
\hline $\begin{array}{c}\text { Temperature, } \\
\text { C. }\end{array}$ & I.S.S.T.4 & $\begin{array}{l}\text { Calcu- } \\
\text { lated } 7 \\
\text { from } \gamma\end{array}$ & $\underset{(1)}{\text { Equation }}$ & $\begin{array}{l}\text { Temperature, } \\
\text { C. }\end{array}$ & I.S.S.T.4 & $\begin{array}{l}\text { Calcu- } \\
\text { lated } 7 \\
\text { from } \gamma\end{array}$ & $\begin{array}{l}\text { Equation } \\
\text { (1) }\end{array}$ \\
\hline $\begin{array}{l}0 \\
50 \\
150 \\
150\end{array}$ & $\begin{array}{c}c m 3 / g \\
206,400 \\
12,060 \\
1,674 \\
393 \\
127.0\end{array}$ & \begin{tabular}{r}
$\mathrm{cm}^{3} / \mathrm{g}$ \\
\hdashline 12,054 \\
$1,674.7$ \\
392.6 \\
127.2
\end{tabular} & $\begin{array}{c}c m^{3} / g \\
206,360 \\
12,043 \\
1,672.9 \\
392.6 \\
127.3\end{array}$ & $\begin{array}{l}250 \\
300 \\
350 \\
374.16\end{array}$ & $\begin{array}{r}c m^{3} / g \\
50.1 \\
21.8 \\
8.9\end{array}$ & $\begin{array}{l}\mathrm{cm}^{3} / g \\
50.06\end{array}$ & $\begin{array}{r}c m^{3 / g} \\
50.10 \\
21.69 \\
9.02 \\
4.39\end{array}$ \\
\hline
\end{tabular}

1 International Skeleton Steam Tables, Mech. Eng., vol. 52, p. 120, 1930.

6 Critical temperature.

7 See fig. 3 for references to data on steam.

Equation (1) applies only along the saturation line, but when it is combined with a vapor pressure equation and some assumption in regard to the form of the isotherms an equation of state applicable over a limited range is obtained. The assumption

$$
P V=R \theta-\frac{b}{V}
$$

where $b$ is a function of temperature is fairly accurate for pressures up to one tenth of the critical pressure. At the saturation line this equation becomes

$$
\pi u^{\prime}=R \theta-\frac{b}{u^{\prime}}
$$

Over the same pressure range the approximation to equation (1)

$$
\log \left(1-\frac{\pi u^{\prime}}{R \theta}\right)=A \log \frac{\pi}{2.718 \pi_{c}}
$$

is sufficiently accurate. Solving for $u^{\prime}$ in equation (7) and substituting: in (6) gives

$$
b=\frac{(R \theta)^{2}}{\pi}\left(\frac{\pi}{2.718 \pi_{c}}\right)^{A}\left[1-\left(\frac{\pi}{2.718 \pi_{c}}\right)^{A}\right]
$$

When the vapor pressure is known equations (8) and (5) suffice for calculating $(P, V, \theta)$ data. If values of $\mathrm{d} \pi / \mathrm{d} \theta$ are also known, calorimetric quantities involving $\mathrm{d} b / \mathrm{d} \theta$ can be calculated. The weight of a normal liter of ammonia calculated in this manner is only 3 parts in 10,000 greater than that observed by Dietrichson, Bircher, and O'Brien. ${ }^{23}$ The calculated rate of change of enthalpy $(H)$ with pressure at constant temperature of ammonia is about 7 percent greater at $0^{\circ} \mathrm{C}$. and zero pressure and 9 percent less at $0^{\circ} \mathrm{C}$. and saturation than the value indicated by the observations of Osborne, Stimson, Sligh, and Cragoe. ${ }^{24}$ The calculated change in $H$ at $0^{\circ} \mathrm{C}$. between zero pressure and saturation is about 3 percent smaller than indicated by the results of those authors. For many substances this method of calculation would be useful for pressures up to one tenth the critical and for temperatures up to the corresponding saturation temperature, since the experimental data in the superheated region are not so accurate or else entirely lacking.

23 J.Am.Chem.Soc., vol. 55, p. 1, 1933.

24 B.S. Sci.Papers (no. 501), vol. 20, p. 65, 1925. 


\section{CONCLUSION}

Provided the vapor pressure temperature relation for the saturated fluid, the critical pressure, and approximate values for liquid densities are known, the specific volume of the saturated vapor can be calculated, except near the critical temperature, with the determination of one empirical constant in the equation

$$
\log _{10}\left(1-\frac{\pi u}{R \theta}\right)\left(1-\frac{\pi u^{\prime}}{R \theta}\right)=A\left(\log _{10} \frac{\pi}{\pi c}\right)-0.4343=A \log _{10} \frac{\pi}{2.718 \pi c}
$$

This relation begins to fail at one fourth to one half the critical pressure, which corresponds to 0.8 to 0.9 the absolute critical temperature. When no data on the specific volume of a substance or of a similar substance are available, the use of $A=0.69$ will give fairly accurate calculated values. Within the limits of experimental error, $A$ has the same value for chemically related substances, hence the value of $A$ may sometimes be deduced from data on a similar substance.

A single value at a well-chosen temperature of the specific volume or of the latent heat of the saturated vapor together with the critical pressure, the vapor pressure, and density of the liquid suffices to determine the value of $A$. Any further data then serves as a check. When data on the vapor over a wide range of pressures are available, equation (1) affords an approximate method for estimating the critical pressure.

When equation (1) is combined with a vapor pressure equation and an appropriate assumption in regard to the form of the isotherms, an equation of state is obtained which is applicable with fair approximation over a limited range and which may be used in absence of more accurate experimental data in the superheated region.

WAshington, June 24, 1933. 